\title{
Synthesis and characterization of thiolated gum ghatti as a novel excipient: Development of compression coated muco- adhesive tablets of domperidone
}

\author{
Vivek Puri 1,2, Ameya Sharma ${ }^{1,2}$, Pradeep Kumar ${ }^{3}$, Inderbir Singh ${ }^{1 *}$, Kampanart Huanbutta ${ }^{4}$ \\ 1 Chitkara College of Pharmacy, Chitkara University, Punjab 140401, India; inder- \\ bir.singh@chitkara.edu.in (I.S.) \\ 2 Chitkara University School of Pharmacy, Chitkara University, Himachal Pradesh 174103, India vi- \\ vek.puri@chitkara.edu.in (V.P.); ameya.sharma@chitkara.edu.in (A.S.) \\ 3 Department of Pharmacy and Pharmacology, School of Therapeutic Sciences, Faculty of Health \\ Sciences, University of the Witwatersrand, Johannesburg 2193, South Africa; pra- \\ deep.kumar@wits.ac.za (P.K.) \\ 4 Faculty of Pharmaceutical Sciences, Burapha University, 169, Saensook, Muang, Chonburi, 20131, \\ Thailand; kampanart@go.buu.ac.th (K.H.) \\ * Correspondence: kampanart@go.buu.ac.th (K.H.); inderbir.singh@chitkara.edu.in (I.S.)
}

Citation: Puri, V.; Sharma, A.; Kumar, P.; Singh, I.; Huanbutta, K. Title. Polymers 2021, 13, x. https://doi.org/10.3390/xxxxx

\begin{abstract}
Background: Mucoadhesive polymers represent a major part of site-specific and localized retention strategies in oral drug delivery. Present research was designed to synthesize and characterize a novel mucoadhesive carbohydrate polymer (thiolated gum ghatti; TGG) which was further employed to fabricate mucoadhesive tablets of domperidone using an industrially viable compression coating technique. Methods: Thiolation of gum ghatti was achieved by the ester formation (esterification) between hydroxyl group and carboxyl group of gum ghatti and thioglycolic acid. Results: TGG was characterized by various physicochemical techniques such as FTIR, XRD, SEM and DSC techniques. In rheological studies, the observed viscosities of pure gum-mucin were 45.45 and $71.75 \mathrm{mPas}$ and that of thiolated gum were 78.7 and $112.58 \mathrm{mPas}$ respectively in water and simulated gastric fluid. Significant increase in viscosity for thiolated gum may be attributed to increased macromolecular interactions responsible for enhanced mucoadhesive potential of thiolated gum. In-silico studies corroborate the role of mucin gum interaction and energetic stabilization for enhanced mucoadhesion properties of thiolated gum. Ex-vivo mucoadhesion strength of gum ghatti and thiolated gum ghatti coated tablets was found to be ranging between $4.67 \pm 0.79$ to $8.99 \pm 0.75 \mathrm{~g}$ and $11.76 \pm 1.34$ to $18.83 \pm 2.07$ g respectively. Conclusion: Thiolated gum ghatti may be regarded as a promising polymer for developing different mucoadhesive drug delivery systems.
\end{abstract}

Keywords: gum ghatti, thiolation, mucoadhesion, tablet, compression coating.

\section{Introduction}

Mucoadhesion is the phenomenon involving interactions between polymer and mucosal surface or mucin. Mucoadhesive interactions lead to the development of strong mucoadhesive bond due to electrostatic, mechanical/ physical crosslinking, chemical bonding, wetting or adsorption interactions [1, 2]. Mucoadhesive drug delivery systems could be designed for active targeting of different biological locations like nasal [3], buccal [4, 5], gastro intestinal [6], rectal [7], vaginal etc [8, 9]. Mucoadhesive polymers could be used alone or in combination for providing suffi- 
cient mucoadhesive property to the drug delivery system $[2,10]$. Polymer composites and chemical modification of polymers could enhance mucoadhesive capacity of the polymers [11].

Gum ghatti is a high molecular weight, anionic polysaccharide obtained from Anogeissus latifolia family Combretaceae. Primary structure of gum ghatti is composed of D-glucuronic acid, D-xylose, D-mannose, D-galactose, and L-arabinose. Gum ghatti is widely used in paper production, pharmaceutical and food industries due to its thickening and emulsification properties. It is employed as sustained release, matrix forming, film forming and mucoadhesive polymer for developing pharmaceutical formulations $[12,13]$.

Thiomers or thiolated polymers are important for mucoadhesive polymers, exhibiting capability to form inter and intra chain disulfide bonds within the polymeric network and strongly improve cohesive properties. Thiol/disulfide chemical reactions with cysteine riched mucin lead to the formation of strong covalent bonds in thiomers $[14,15]$. Thiomers when compared with the unmodified polymers show strong adhesive strength which is sufficient to localize dosage form at a given specific site for a prolonged period of time. Apart from improvement in mucoadhesive properties thiolated polymers have also been reported to exhibit permeation enhancing, enzyme inhibition, controlled release, and thermal stability effects [16]. Thiolation procedure have been successfully implemented for enhancing the mucoadhesive potential of various gums viz. karaya gum [17], moringa gum [18], xanthan gum [19], gellan gum [20], tamarind gum [21], and psyllium husk [22]. To the best of our knowledge; thiolation of gum ghatti and its mucoadhesive potential has not been reported in the literature.

The present research was intended to perform the synthesis of thiolated gum ghatti followed by characterization of modified gum by various techniques such as Fourier transform infrared spectroscopy (FTIR), Differential scanning calorimetry (DSC), X-ray diffraction analysis (XRD), and Scanning electron microscopy (SEM). Rheological studies were performed to observe the behavior of the polymer and sensitivity at given temperatures. The molecular transitions within the polymer were characterised using molecular mechanics analysis. Polymer mucin interaction study indicates the mucoadhesion property of modified gum in comparison to native gum. Domperidone core tablets were press coated with pure gum ghatti and thiolated gum ghatti. The formulated compression coated tablets were evaluated for various parameters, ex-vivo mucoadhesion and in-vitro drug release studies.

\section{Materials and Methods}

Gum ghatti was gifted by Hydrocolloid Plantations (New Delhi, India). Domperidone was kindly gifted by Kwality Pharmaceuticals, Amritsar, Punjab, India. Thioglycolic acid, potassium dihydrogen orthophosphate and sodium chloride were acquired from Loba Chemie Pvt. Ltd. (Mumbai, India). 1-Ethyl-3-(3-Dimethylaminopropyl)carbodiimide Hydrochloride (EDAC), 5,5'-dithiobis-(2-nitrobenzoic acid) or DTNB (Ellman's Reagent)and Dialysis membrane (width- $31.13 \mathrm{~mm}$ and diameter- $21.5 \mathrm{~mm}$ ) were received from Hi-Media Laboratories Pvt. Ltd. (Mumbai, India).

\subsection{Synthesis of Thiolated Gum Ghatti}

Pure gum ghatti (2 g) was firstly dissolved in $50 \mathrm{~mL}$ of deionized water, followed by the addition of EDAC (50 mM) and thioglycolic acid (4 g). The aforementioned reaction mixture was kept undisturbed for $3 \mathrm{hr}$ at room temperature. Further, the reaction mixture was added in dialysis membraneand dialyzed against $5 \mathrm{mM}$ 
hydrochloric acid $(\mathrm{HCl})$ at $10 \pm 1^{\circ} \mathrm{C}$ for $1 \mathrm{hr}$, against $5 \mathrm{mM} \mathrm{HCl}$ containing sodium chloride (1\%) for $2 \mathrm{hr}$ at room temperature and against $1 \mathrm{mM} \mathrm{HCl}$ containing sodium chloride (1\%) for $2 \mathrm{hr}$ at room temperature. Afterwards, the reaction mixture was collected and lyophilized (Allied frost, Delhi, India) at $-30 \pm 1{ }^{\circ} \mathrm{C}$ under 10.01 mbar pressure and the mixture were kept at $+4{ }^{\circ} \mathrm{C}$ [23]. Chemical reaction depicting the synthesis of thiolated polymer is shown in Figure 1.

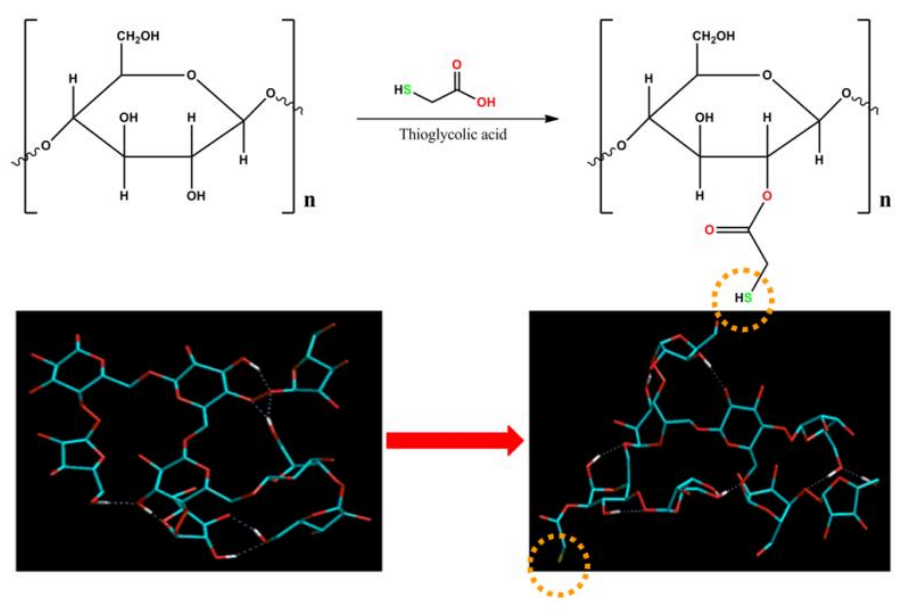

Figure 1. Chemical synthesis of thiolated biopolymer

Using Ellman's reagent, the degree of thiol group substitution was measured [24]. The amount of accurately weighed thiolated gum ghatti $(50 \mathrm{mg})$ was dissolved in water $(25 \mathrm{ml})$. Aliquot $(2.5 \mathrm{ml})$ was taken from the above prepared solution and was diluted with $2.5 \mathrm{ml}$ of $0.5 \mathrm{M}$ phosphate buffer ( $\mathrm{pH}$ 8.0) and was allowed to react with $5 \mathrm{ml}$ of Ellman's reagent for two hours. The absorbance of reaction mixture was measured using UV spectrophotometer at $450 \mathrm{~nm}$. The total number of thiol groups was calculated using the standard curve of thioglycolic acid with Ellman's reagent.

\subsection{Characterization}

\subsubsection{Fourier Transform Infrared Spectroscopy (FTIR)}

Powder samples of pure gum ghatti and thiolated gum ghatti were subjected to FTIR analysis using FTIR spectrophotometer (Alpha, Bruker, Japan). Sample pellets were prepared with $\mathrm{KBr}$ and FTIR spectra were recorded in the frequency range of $4000-400 \mathrm{~cm}^{-1}$. The possible interactions between the drug and different components of the tablet formulation were also evaluated by FTIR analysis.

\subsubsection{Differential Scanning Calorimetry (DSC)}

DSC thermograms of pure gum ghatti and thiolated gum ghatti were recorded using differential scanning calorimeter (MettlerToledo Star System, 305, Switzerland). A required amount of sample was crimped in a standard aluminium pan and heated over a temperature range of $40^{\circ} \mathrm{C}$ to $300^{\circ} \mathrm{C}$ at a heating rate $10^{\circ} \mathrm{C}$ per minute in a nitrogen atmosphere.

\subsubsection{X-Ray Diffraction Analysis (XRD)}

$\mathrm{X}$-ray diffraction patterns of pure gum ghatti and thiolated gum ghatti were traced/recorded using X-ray diffractometer (Miniflex 2, Rigaku, Japan) with Ni filtered $\mathrm{Cu}(\mathrm{K}-\alpha)$ radiations, with voltage rate of $45 \mathrm{kV}$, and a current of $40 \mathrm{~mA}$. The samples (gum ghatti and thiolated gum ghatti) were analyzed over $2 \theta$ range of $0^{\circ}$ to 
$80^{\circ}$ with scan step size of $0.0170^{\circ}(2 \theta)$, scan step time of $25 \mathrm{~s}$ and scan speed 0.05 $\min ^{-1}$.

\subsubsection{Scanning Electron Microscopy (SEM)}

The external morphology (shape and surface) of gum ghatti and thiolated gum ghatti was determined by scanning electron microscope (Joel, fine coat ion sputter, JFC-1100). Double sided adhesive tape is used to adhere the gold palladium alloy $\left(150-200 \mathrm{~A}^{\circ}\right)$ coated samples onto the stubs of microscope.

\subsubsection{Rheological Measurements}

Rheological behavior of gum ghatti and thiolated gum ghatti was analyzed using rheometer (MCR 92, Anton Paar, Austria).For temperature sweep analysis, samples were analyzed in temperature range of $20^{\circ} \mathrm{C}$ to $60{ }^{\circ} \mathrm{C}$ with $2{ }^{\circ} \mathrm{C} / \mathrm{min}$ constant shear rate of $10 \mathrm{~s}^{-1}$. The samples were carried out under shear rate sweep analysis ranging from 0.1 to $1000 \mathrm{~s}^{-1}$ to evaluate the flow behavior, with a data acquisition duration varying from $30 \mathrm{sec}$ on a logarithmic scale at a constant temperature of 25 ${ }^{\circ} \mathrm{C}[25]$.

\subsubsection{Polymer Mucin Interaction Study}

For polymer-mucin interaction study pure gum (gum ghatti) $(1 \% \mathrm{w} / \mathrm{v})$, thiolated gum (gum ghatti) $(1 \% \mathrm{w} / \mathrm{v})$, and mucin $(5 \% \mathrm{w} / \mathrm{v})$ solutions were prepared in SGF (simulated gastric fluid) medium without enzymes [26]. The experiments (viscometric) were performed on pure gum, thiolated gum, mucin, pure gum mucin mixture and thiolated gum mucin mixture solutions. All the mixture solutions were allowed to stand for at least $1 \mathrm{hr}$ at $37.0 \pm 0.1^{\circ} \mathrm{C}$ (prior to analysis). The rheological measurements were performed using Brookfield viscometer (Model DV-III, Brookfield, USA). Each sample (mixture solutions) was added to the viscometer and equilibrated for $2 \mathrm{~min}$. The measurement was made with the shear rate up to about $25 \mathrm{~s}^{-1}$ which were given as per following equation

$$
\tau=K_{c} Y^{\mathrm{n}}
$$

Where $\tau$ is the shear stress and is the shear rate. Apparent viscosity was measured at a shear rate of $3.96 \mathrm{~s}^{-1}$

Effect of mucin and polymer on viscosity enhancement was studied by various parameters of viscosity like expected viscosity $\left(\eta_{\exp }\right)$, observed viscosity

$\left(\mathrm{n}_{\text {obs }}\right)$, enhanced viscosity $\left(\mathrm{n}_{\text {enhance }}\right)$ and the relative viscosity $\left(\mathrm{n}_{\text {rel }}\right)$ which were calculated as per following equations:

$$
\begin{gathered}
\eta_{\text {exp }}=\eta_{p}+\eta_{m} \\
\eta_{\text {enhance }}=\eta_{o b s}-\eta_{\text {exp }} \\
\eta_{\text {rel }}=\eta_{o b s} \div \eta_{\text {exp }}
\end{gathered}
$$

Where and are the viscosity of polymer and mucin respectively. While the polymer-mucin interaction was studied by the force of mucoadhesion by using the formula

$$
F=\mathrm{\eta}_{b} \sigma
$$


$\mathrm{F}$ is the force of mucoadhesion, is viscosity components of bioadhesion, and is shear rate $\left(\mathrm{s}^{-1}\right)$ [26]. For in-silico evaluation; gum ghatti and thiolated gum ghatti were interacted with glycosylated mucin (Avogadro 1.2 platform) using molecular mechanics simulations (MM+ force field; Polak-Ribere conjugate gradient; ChemLite3.0., FL, USA) [27].

\subsubsection{In-vivo Toxicity Study}

For in-vivo toxicity study, Wistar rats (150-200 g body weight) were obtained from Lala Lajpat Rai University of Veterinary \& Animal Sciences, India and were kept under standard housing conditions following balanced diet and water ad libitum. The study protocol was approved by the animal ethics committee of the institute (Reg.No. 1181/PO/ReBi/S/08/CPCSEA; vide Protocol No. IAEC/CCP/20/01/PR-004). The single dose in vivo acute oral toxicity study on pure gum ghatti and thiolated gum ghatti was performed as per Organization for Economic Co-operation and Development (OECD) 423 guidelines. The animals were divided into five different groups, Group-I (control group; n=3), Group-II (pure gum ghatti; Dose- 300 mg/kg; n= 3), Group-III (thiolated gum ghatti; Dose- 300 mg/kg; $\mathrm{n}=3$ ), Group-IV (pure gum ghatti; Dose- $2000 \mathrm{mg} / \mathrm{kg}$; $\mathrm{n=3}$ ), Group-V (thiolated gum ghatti; Dose- $2000 \mathrm{mg} / \mathrm{kg} ; \mathrm{n}=3$ ) and the sample was administered per orally by feeding needles made of stainless steel. On the 14th day of the experimental procedure, animals were sacrificed by cervical dislocation for histological examination of stomach and intestine [28, 29].

\subsection{Preparation of Core Tablet of Domperidone}

Core tablet $(80 \mathrm{mg})$ of domperidone was formulated using domperidone (10 $\mathrm{mg}$ ) as an active ingredient and Avicel 112 (63 mg), PVP K30 (5 mg), Talc (1 mg), magnesium stearate $(1 \mathrm{mg})$ as tablet excipients. All ingredients were sieved (60\#), and blended using double cone blender for 15-20 min. Tablets with $80 \mathrm{mg}$ weight were prepared using multiple station tablet punching machine equipped with $6 \mathrm{~mm}$ concave round die-punch tooling (A.K. Industries, Nakodar, India) [30, 31].

\subsection{Compression Coating of Core Tablets}

An appropriate blend of coating polymer (pure gum ghatti and thiolated gum ghatti) was press coated over the formulated core tablet as per the composition given in Table 1. Avicel-112 was added quantity sufficient for making the total tablet weight equal to $600 \mathrm{mg}$. The die cavity was first half filled with polymer (coating material), then core tablet was placed in the die, and remaining coating material was added over the core tablet. Compression coating was performed using multipunch tableting machine having $8.5 \mathrm{~mm}$ concave punches at an applied force of $5000 \mathrm{~kg}$ [31, 32].

Table 1. Compression coating composition for mucoadhesive tablet batches of pure gum ghatti and thiolated gum ghatti

\begin{tabular}{lccccc}
\hline Batches & $\begin{array}{l}\text { Gum Ghatti } \\
(\mathbf{m g})\end{array}$ & $\begin{array}{l}\text { Thiolated } \\
\text { Gum Ghatti } \\
(\mathbf{m g})\end{array}$ & $\begin{array}{l}\text { Avicel 112 } \\
(\mathbf{m g})\end{array}$ & $\begin{array}{l}\text { PVP K30 } \\
(\mathbf{m g})\end{array}$ & $\begin{array}{l}\text { Talc } \\
(\mathbf{m g})\end{array}$ \\
\hline F1GG & 350 & - & 145 & 20 & 5 \\
F2GG & 400 & - & 95 & 20 & 5 \\
F3GG & 450 & - & 45 & 20 & 5 \\
F4GG & 500 & - & - & 20 & 5 \\
\hline
\end{tabular}




\begin{tabular}{llcccc}
\hline F1TGG & - & 350 & 145 & 20 & 5 \\
F2TGG & - & 400 & 95 & 20 & 5 \\
F3TGG & - & 450 & 45 & 20 & 5 \\
F4TGG & - & 500 & - & 20 & 5 \\
\hline
\end{tabular}

\subsection{Evaluation of Core and Compression Coated Tablets}

To ensure the uniformity and mechanical integrity of prepared tablets of pure gum ghatti and thiolated gum ghatti, the following parameters like thickness, weight variation, friability, drug content, in-vitro release study and ex-vivo mucoadhesion strength were measured.

\subsubsection{Hardness and Friability}

Hardness and friability of 20 tablets were measured using the Monsanto hardness tester (Model VMT- 1, VinSyst Technologies, Mumbai, India) and the Roche friabilator (Campbell Electronics, Mumbai, India), respectively. Pre-weighed tablets were placed in the friabilator. The friability test machine (Roche friabilator) was rotated at the rate of $25 \mathrm{rpm}$ (100 revolutions). Afterwards, tablets were again weighed and the values were calculated using formula given below.

$$
\mathrm{F}=\frac{\text { Initial weight }- \text { Final weight }}{\text { Initial weight }} X 100
$$

\subsubsection{Thickness}

The thickness of formulated tablets was deliberately considered using Digital Vernier Caliper (Mitutoyo Absolute Digimatic Calliper, Japan). From each formulated batch, five tablets were taken and average value was calculated.

\subsubsection{Drug Content}

The formulated tablets were weighed individually and crushed in mortar and pestle. The powder equivalent to average weight of tablets was initially weighed and then transferred to volumetric flask containing buffer solution $(0.1 \mathrm{~N} \mathrm{HCl})$. The dispersion was stirred for at least 2-3 hr followed by filtration using Whatman filter paper. The drug content was observed at absorbance $287 \mathrm{~nm}$ after dilution using UV-Vis double beam spectrophotometer (AU 2701, Systronics, Mumbai, India).

\subsubsection{Ex-Vivo Determination of Mucoadhesive Strength}

Mucoadhesion testing of compressed coated tablets of domperidone was done using two different polymers (gum ghatti and thiolated gum ghatti) and was executed employing texture analyzer (TA.XT plus, Stable MicroSystems, UK). Tablet was attached to cylindrical probe with the help of double side adhesive tape. The pig stomach (tissue) was equilibrated at $37.0 \pm 0.5^{\circ} \mathrm{C}$ for $15 \mathrm{~min}$ before placing onto the holder stage. The probe attached with tablet was dispersed into the medium for framed time proceeding to the test. Afterwards, the hydrated disc was shifted to downward direction to get in contact with rinsed tissue at a defined force and sustained until time specified. The probe was uplifted at predetermined test speed and maximum detaching force $\left(\mathrm{F}_{\max }\right)$ that required to separate the tablet equipped with probe from tissue which can be determined from software (Texture Exponent 32). The precursor settings of the instrument were tested with different parameters such as test speed $(0.5 \mathrm{~mm} / \mathrm{s})$, contact time $(60 \mathrm{~s})$, contact force $(1.0 \mathrm{~N})$ and distance (15 $\mathrm{mm}$ ). Probe without attached sample (tablet) was also assessed to examine the animal tissue uniformity [33]. 


\subsubsection{In-Vitro Drug Release}

In-vitro dissolution study of compressed domperidone tablets was executed using USP-II Paddle type dissolution apparatus (DS 8000, LabIndia, India) with a rotating speed (50 rpm at $37 \pm 0.5{ }^{\circ} \mathrm{C}$ ) using dissolution medium $0.1 \mathrm{~N} \mathrm{HCl}(\mathrm{pH} 1.2)$. At fixed time intervals, samples $(5 \mathrm{ml})$ were taken out and filtered through membrane filter $(0.45 \mu \mathrm{m})$. Further it was diluted and analyzed using UV double beam spectrophotometer (AU 2701, Systronics, Mumbai, India) at $287 \mathrm{~nm}$. Drug release cumulative percentage was deliberated using an equation derived from calibration curve. Pharmacokinetic models such as Zero order, First order, Higuchi, Kosmeyer-Peppas and Hixon-Crowell were fitted with release data of prepared tablets to perceive kinetic drug release modeling [34].

\section{Results}

Thiolation processes can strengthen the mucoadhesive properties of natural gums. In the present research thiolation of gum ghatti was performed followed by characterization of the synthesized thiomers. Thiolated gum ghatti was found to contain $4.5 \mathrm{mM}$ of thiol groups/g of polymer as determined by Ellman's method.

FTIR spectra of gum ghatti and thiolated gum ghattiare depicted in Figure 2A. The FTIR spectra of gum ghatti shows stretching vibration of $-\mathrm{OH}$ at $3441.74 \mathrm{~cm}^{-1}$, $-\mathrm{OH}$ at $3161.30 \mathrm{~cm}^{-1},-\mathrm{CH}$ at $2932.40 \mathrm{~cm}^{-1}, \mathrm{C}=\mathrm{O}$ alkene at $1669.32 \mathrm{~cm}^{-1}, \mathrm{C}-\mathrm{H}$ alkane at $1450.02 \mathrm{~cm}^{-1}$ and $1035.51 \mathrm{~cm}^{-1}$ attributed to $\mathrm{C}-\mathrm{O}$ primary alcohol [35]. All the characteristic peaks of gum ghatti were found in thiolated gum ghatti. However, the presence of additional -SH stretch at $2571.48 \mathrm{~cm}^{-1}$ confirms the thiolation of gum ghatti. Thiolationof gum ghatti was authorized by the formation of ester bonds between carboxyl group of thioglycolic acid and hydroxyl group of gum ghatti [17, $36,37]$.

Figure 2B shows DSC thermogram of gum ghatti and thiolated gum ghatti. The thermogramof pure gum ghatti shows endothermic peak at $64.42{ }^{\circ} \mathrm{C}$ (onset 53.97 ${ }^{\circ} \mathrm{C}$, endset $81.97{ }^{\circ} \mathrm{C}$, enthalpy $-39.36 \mathrm{~mJ} / \mathrm{g}$ ) and $183.73{ }^{\circ} \mathrm{C}$ (onset $182.93{ }^{\circ} \mathrm{C}$, endset $185.38{ }^{\circ} \mathrm{C}$, enthalpy $0.16 \mathrm{~mJ} / \mathrm{g}$ ). DSC thermogram of thiolated gum ghatti depicts endothermic peaks at $199.73{ }^{\circ} \mathrm{C}$ (onset $198.39{ }^{\circ} \mathrm{C}$, endset $200.55^{\circ} \mathrm{C}$, enthalpy -0.24 $\mathrm{mJ} / \mathrm{g}$ ) and $206.39{ }^{\circ} \mathrm{C}$ (onset $204.43{ }^{\circ} \mathrm{C}$, endset $207.62{ }^{\circ} \mathrm{C}$, enthalpy $-1.41 \mathrm{~mJ} / \mathrm{g}$ ). The increase in endothermic transition temperature and heat of fusion in thiolated gum ghatti indicated thiol modification of gum ghatti[19].

X-ray diffractogram (Figure 2C) of gum ghatti is typical amorphous material with a broad characteristic peak at 19.97, while the diffractogram of thiolated gum ghatti depicts sharp peaks at 27.41, 31.75, 45.52, 56.52, 66.26, 75.30 and 84.00 (20), indicating significant crystalline behavior of the modified gum [38]. 


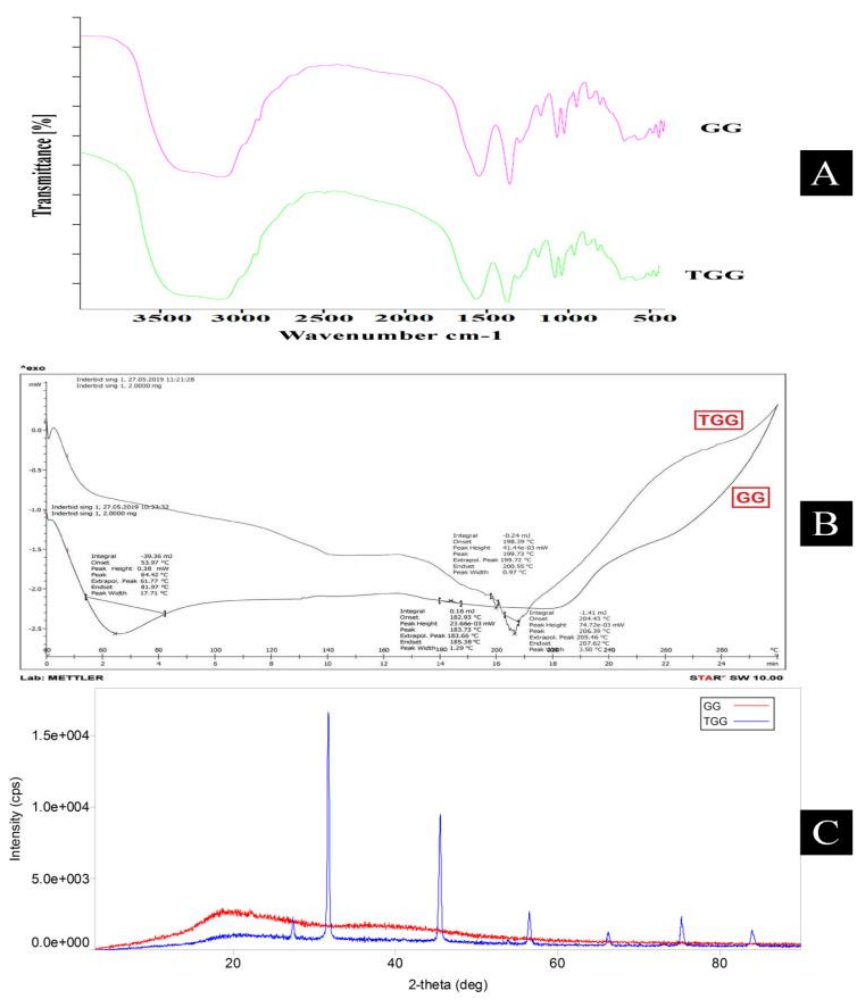

Figure 2. (A) FTIR spectra of pure gum ghatti and thiolated gum ghatti; (B) DSC thermogram of pure gum ghatti and thiolated gum ghatti; (C) XRD diffractogram of pure and thiolated gum ghatti

SEM technique examined the surface morphology of gum ghatti and thiolated gum ghatti (Figure 3). SEM of pure gum ghatti indicates the presence of polyhedral flakes with rough surface morphology. However, thiolated gum ghatti shows sharp lucent crystalline flakes with relatively smooth surface. Relative smooth surface of thiolated gum ghatti may be helpful in providing larger surface area for interaction with mucosal layer and hence responsible for enhanced mucoadhesive interaction. The results are in-line with the findings reported by Ahuja and his co-workers [18].
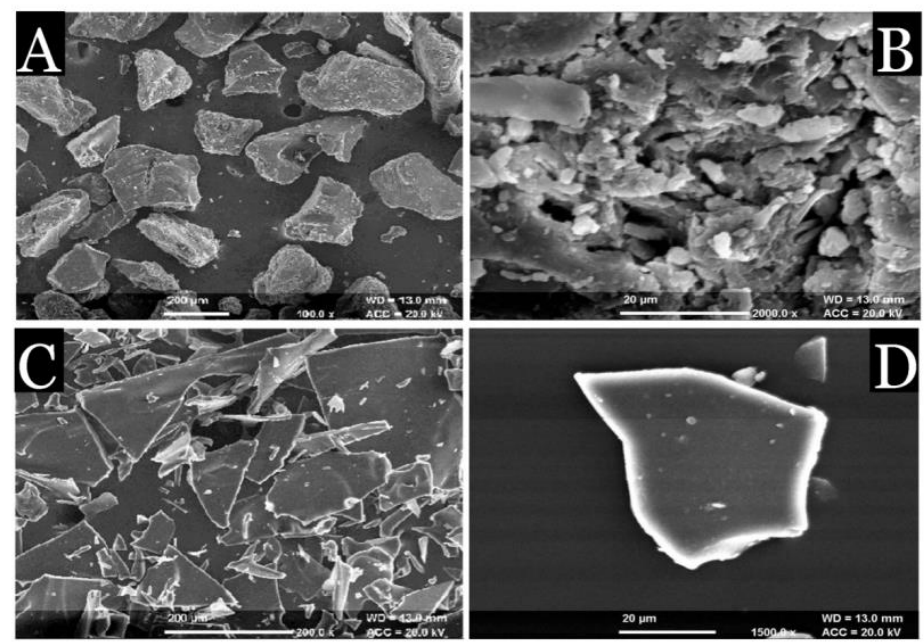

Figure 3. SEM images of pure gum ghatti (A, B) and thiolated gum ghatti (C, D) at different magnifications

Gum ghatti and thiolated gum ghatti were evaluated for rheological measurements and were studied for shear rate sweep and temperature sweep analysis as shown in Figure 4(A \& B). Pure gum ghatti was observed to show almost Newto- 
nian behavior. Sample of thiolated gum ghatti was found to exhibit shear thinning behavior across the given experimental conditions due to the orientation of the microstructures in the direction of given deformation [39].

Pure gum ghatti was observed to be sensitive to the given temperatures as continuous drop in viscosity could be perceived from Figure 4(B). However, viscosity of thiolated gum ghatti was found to be unaffected with the increase in temperature. It may be deduced that the viscosity and hence mucoadhesive property of thiolated gum are not affected by temperature rise when compared with pure gum ghatti. The DSC results indicating increased endothermic transition temperature and heat of fusion in thiolated gum ghatti also corroborate with the temperature sweep analysis results.
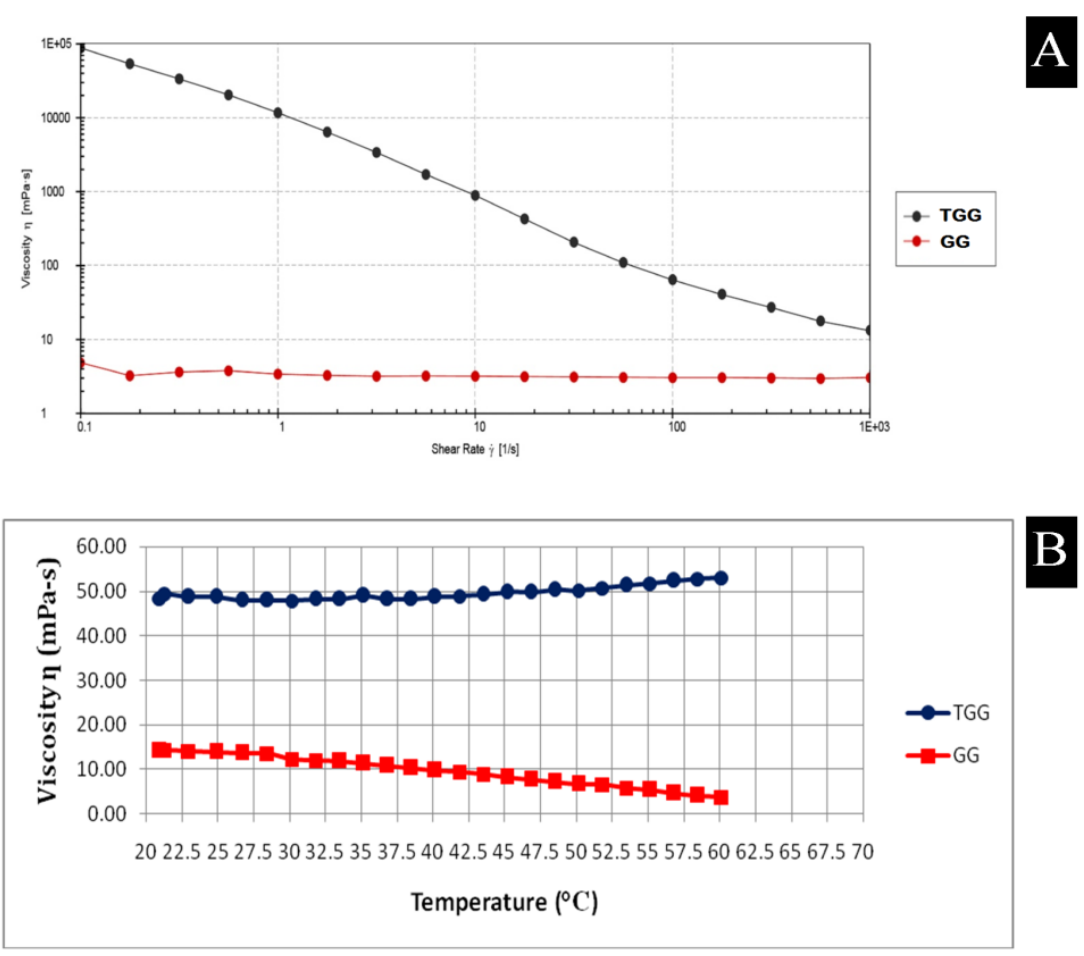

Figure 4. Rheological measurements A) Shear rate sweep analysis $(n=3)$ and B) Temperature sweep analysis $(n=3)$

The significant enhancement in mucoadhesive interactions is reported between mucin and native gum/ thiolated gum in simulated gastric fluid. It prominently indicates that native gum/ thiolated gum is $\mathrm{pH}$ dependent, shows molecular interaction and viscosity enhancement in SGF. Viscosity of mucin, pure gum (gum ghatti), thiolated gum (gum ghatti), mucin and gum (mucin + pure gum), mucin and thiolated gum (mucin + thiolated gum) in water was found to be 7.65, 21.62, 34.20, 45.45 and $78.70 \mathrm{mPa}$ s and in SGF 11.85, 34.90, 55.11, 71.75 and $112.58 \mathrm{mPa}$ s respectively. Mixture of mucin and pure gum in water exhibited 29.27 and $45.45 \mathrm{mPa}$ s value of Пexp and Пobs respectively with Пenhance of $16.18 \mathrm{mPa}$. Similarly, the mixture of mucin and thiolated gum showed Пexp and Пobs to be 41.85 and $78.70 \mathrm{mPa}$ s with Пenhance of $24.85 \mathrm{mPa}$ s respectively. In SGF the mixture of mucin and thiolated gum showed Пexp and Пobs to be 66.96 and $112.58 \mathrm{mPa} s$ with Пenhance of 45.62 $\mathrm{mPa} s$ respectively. The bioadhesion force of mucin and gum (mucin + pure gum) and mucin and thiolated gum (mucin + thiolated gum) in water was found to be 
64.07 and $98.41 \mathrm{mPa}$ and in SGF 99.00 and $180.65 \mathrm{mPa}$ respectively (Table 2 \& 3).The bioadhesion force however, seems to depend on the initial viscosity and environmental $\mathrm{pH}$. The bioadhesion force of pure and thiolated gum ghatti with mucin was high at lower $\mathrm{pH}$ (SGF), contrast to that in water [26]. These observations were corroborated by in silico mucoadhesion profiling wherein it increases in various viscosity components of thiolated gum can be attributed to molecular interactions between the macromolecules. TGG-MUC (thiolated gum ghatti-mucin) complex showed much higher energy of stabilization (total energy) on contrast to GG-MUC (gum ghatti-mucin) complex (proteosaccharide). The energetic and geometrical stabilization were mainly attributed to electrostatic interactions. Interestingly, while GG-MUC was supported by OH-HO hydrogen bonding; TGG-MUC interaction included -OH-HN- and -SH-HN-H- bonding and hence better mucoadhesion profile (Figure 5).

Table 2. Apparent viscosity of samples in water and SGF at shear rate $3.96 \mathrm{~s}^{-1}$ and total minimized energy.

\begin{tabular}{|c|c|c|c|c|}
\hline S.No. & Sample & $\begin{array}{c}\text { Viscosity (mPa s) } \\
\text { (in water) }\end{array}$ & $\begin{array}{c}\text { Viscosity (mPa s) } \\
\text { (in SGF) }\end{array}$ & $\begin{array}{c}\text { Total minimized } \\
\text { energy (MM+) }\end{array}$ \\
\hline 1. & Mucin (5\%) & 7.65 & 11.85 & -166.81 \\
\hline 2. & Pure Gum (1\%) & 21.62 & 34.90 & -39.48 \\
\hline 3. & Thiolated Gum (1\%) & 34.20 & 55.11 & -13.73 \\
\hline 4. & Mucin + Pure Gum & 45.45 & 71.75 & -258.41 \\
& & & & $(\Delta \mathrm{E}=-52.12)$ \\
\hline 5. & Mucin + Thiolated Gum & 78.70 & 112.58 & -267.84 \\
& & & & $(\Delta \mathrm{E}=-87.29)$ \\
\hline
\end{tabular}

Table 3. Different parameters of viscosities, expected viscosity (Пexp), observed viscosity (Пobs), enhanced viscosity (Пenhance), the relative viscosity (Пrel) and force of bioadhesion was calculated in water and in SGF

\begin{tabular}{|l|c|c|c|c|}
\hline \multirow{2}{*}{ Parameter } & \multicolumn{2}{|c|}{ Water } & \multicolumn{2}{c|}{ SGF } \\
\cline { 2 - 5 } & Mucin + Pure & Mucin + Thiolated & Mucin + Pure & Mucin + Thiolated \\
& gum & gum & 46.75 & gum \\
\hline$\eta_{\exp }(\mathrm{mPa} s)$ & 29.27 & 41.85 & 71.75 & 66.96 \\
\hline$\eta_{\text {obs }}(\mathrm{mPa} s)$ & 45.45 & 78.70 & 25 & 112.58 \\
\hline$\eta_{\text {enhance }}(\mathrm{mPa})$ & 16.18 & 24.85 & 1.53 & 45.62 \\
\hline$\eta_{\text {rel }}(\mathrm{mPa} s)$ & 1.55 & 1.88 & 99 & 1.68 \\
\hline F $(\mathrm{mPa})$ & 64.07 & 98.41 & & 180.65 \\
\hline
\end{tabular}

Interaction of thiolated gum with mucin resulted in the formation of strong mucoadhesive bond via disulfide exchange. Formation of inter and/ or intra molecular disulfide bonds could be held responsible for enhances mucoadhesive and drug release retardant property of thiolated gum. Similarly findings of solubility, dissolution, prolonged residence time and increased mucoadhesive property were reported by Nowak et al. and Jalil et al. [40, 41]. 
Esterification between hydroxyl groups in gum ghatti and sulphur groups in TGA was achieved by the covalent bond attachment of thioglycolic acid to gum ghatti. The mean yield of thiolated gum ghatti was found to be $92 \%$ after optimizing critical process parameters.
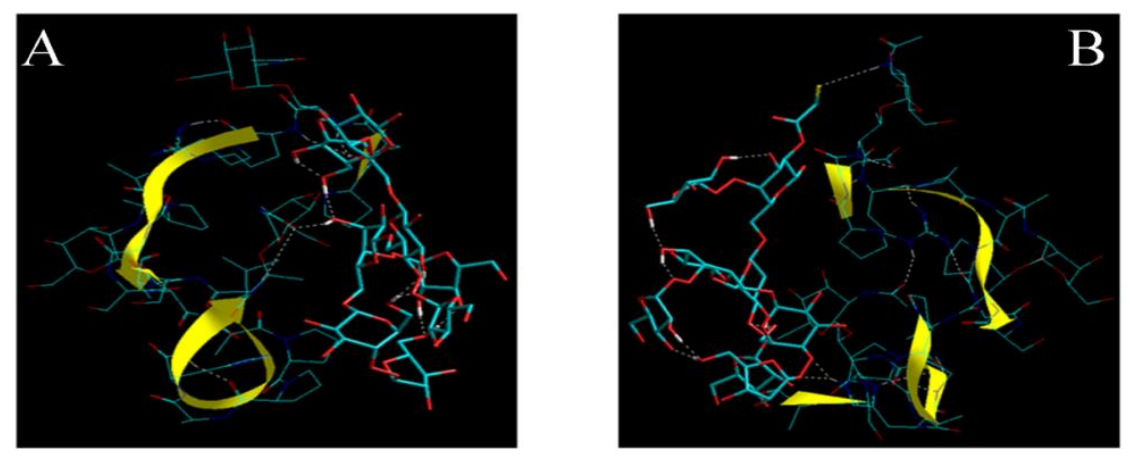

Figure 5. In-silicomucoadhesion visualization of A) Gum Ghatti and B) Thiolated Gum Ghatti with glycosylated mucin (stick rendering with yellow ribbon). The gum and its derivative are represented by tube rendering. The $\mathrm{H}$-bonds are represented by white broken lines (- - -).

Histopathological images of stomach and intestine tissues of rats after oral administration of gum ghatti and thiolated gum ghatti are shown in Figure 6. In the histopathological images of stomach, the gastric glands surface epithelium was found normal with no ulcerative spots. No deformations were observed in lacteals and goblet cells of duodenum. Further, villi and microvilli (hair like projections) were in normal condition. It was affirmed that both stomach and intestine tissues did not show any evidence of toxicity after single oral dose $(300 \mathrm{mg} / \mathrm{kg}$ and $2000 \mathrm{mg} / \mathrm{kg}$ body weight) oral administration of pure and thiolated gum ghatti in Wistar rats. 


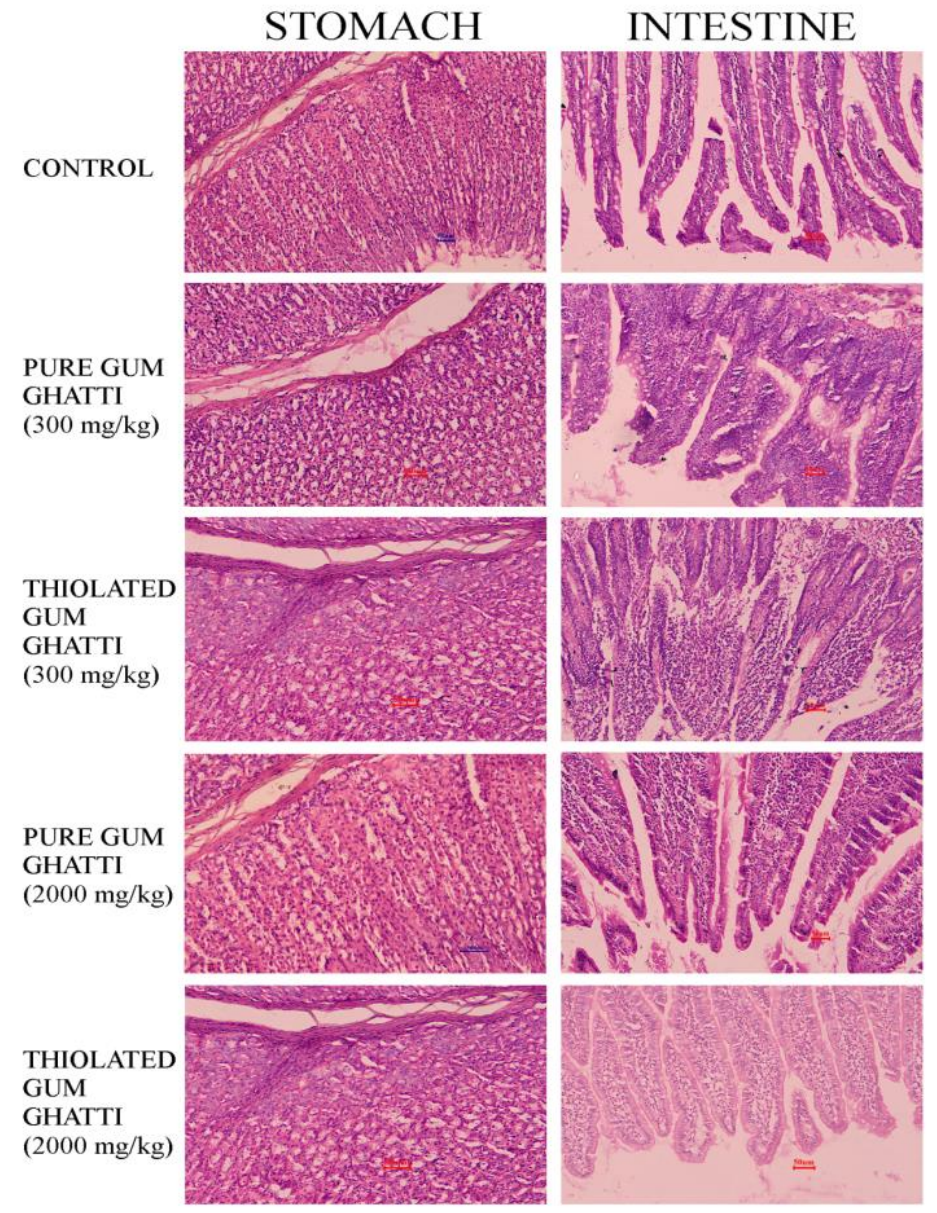

Figure 6. Histopathological examination of stomach and intestine tissues of Wistar rats. Row 1: Control; Row 2: Pure gum ghatti $(300 \mathrm{mg} / \mathrm{kg})$; Row 3: Thiolated gum ghatti (300 mg/ kg); Row4: Pure gum ghatti $(2000 \mathrm{mg} / \mathrm{kg})$; Row 5: Thiolated gum ghatti $(2000 \mathrm{mg} / \mathrm{kg})$.

\subsection{Evaluation of Core Tablets}

Various evaluation parameters were resulted for core tablets. The inner core tablets of domperidone were found to be $80 \pm 5 \mathrm{mg}$ in weight. The thickness of the core tablets was found be $1.82 \pm 0.10 \mathrm{~mm}$, hardness and friability of core tablets were $3.7 \pm 0.50 \mathrm{~kg} / \mathrm{cm}^{2}$ and $0.79 \pm 0.15 \%$.The evaluation indicated significant quality attributes in core tablets. All assessments were performed in triplicate $(n=3)$.

\subsection{Evaluation of Compression Coated Tablets}

\subsubsection{Ex-vivo Determination of Mucoadhesive Strength}

The coated tablets were compressed and prepared using gums (pure and thiolated) in varied proportions to coat formerly prepared inner core tablets of domperidone. The detachment force $\left(\mathrm{F}_{\max }\right)$ of F1GG to F4GG was found to be between $4.67 \pm 0.79$ and $8.99 \pm 0.75 \mathrm{~g}$. The $\mathrm{F}_{\max }$ for F1TGG to F4TGG was found to ranging between $11.76 \pm 1.34$ and $18.83 \pm 2.07 \mathrm{~g}$. The results depicted a notable increase in mucoadhesive property of thiolated gum compared to pure gum. Additionally, mucoadhesive strength was directly proportional to the concentration of thiolated gum which was used as coating material for developing mucoadhesive tablets of domperidone.

3.2.2. In-vitro Drug Release 
For comparing drug release rates in-vitro dissolution study was performed on core tablets and core tablets coated with gum ghatti and thiolated gum ghatti in different concentration as showing in Figure 7. Core tablet released $80.19 \%$ and $94.63 \%$ domperidone in 30 and 60 min respectively. Core tablets compression coated with gum ghatti (F4GG) depicted 51.85\% and 95.33\% drug release in 0.5 and $6 \mathrm{~h}$ respectively. However core tablets coated with thiolated gum ghatti (F4TGG) exhibited $35.28 \%$ and $78.95 \%$ drug release after 0.5 and $6 \mathrm{~h}$ respectively. The significantly improved drug release retardant properties of thiolated gum ghatti compared to pure gum ghatti could be attributed to increased polymer crosslinking after thiolation due to the formation of inter/intra chain di-sulphide bonds. This may increase the drug diffusional path length with in the polymer matrix resulting in better controlled/ sustained drug release property of the modified gum. Compression coated batches F1GG, F2GG, F1TGG, and F2TGG exhibited first order to be the best fitted model. However batches F3GG, F4GG, F3TGG, and F4TGG displayed Korsmeyer-Peppas to be the best obeyed model. This could be deduced that at lower polymer concentration, the best fit model is First order and at higher polymer concentration Korsmeyer-Peppas is the best fit model for explaining the mechanism of drug release from the formulation as shown in Table $4[42,43]$.
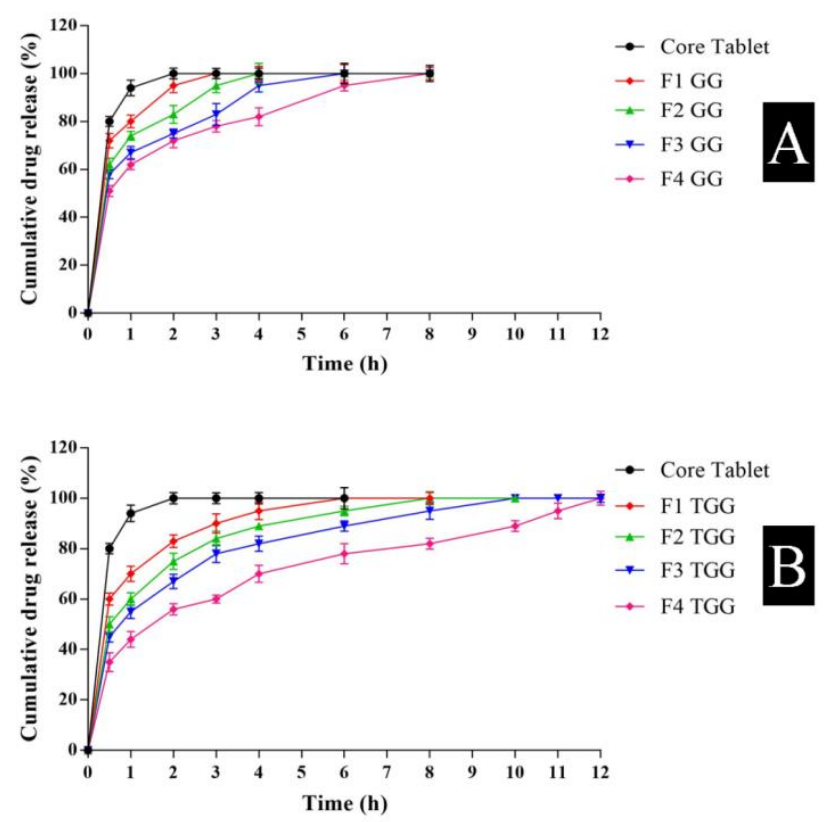

Figure 7. In vitro drug release from core tablet and different batches of compression coated tablets of A) Gum ghatti $(n=3)$ and B)thiolated gum ghatti $(n=3)$

Table 4. In vitro drug release data of the formulated batches

\begin{tabular}{|c|c|c|c|c|c|c|c|c|c|c|c|}
\hline \multirow[t]{2}{*}{ Batches } & \multicolumn{2}{|c|}{ Zero Order } & \multicolumn{2}{|c|}{ First Order } & \multicolumn{2}{|c|}{ Higuchi Model } & \multicolumn{2}{|c|}{$\begin{array}{c}\text { Hixson Crowell } \\
\text { Model }\end{array}$} & \multicolumn{3}{|c|}{$\begin{array}{c}\text { Korsmeyer-Peppas } \\
\text { Model }\end{array}$} \\
\hline & $\mathrm{r}^{2}$ & $\mathrm{k}_{\mathrm{o}}$ & $\mathrm{r}^{2}$ & $\mathrm{k}_{1}$ & $\mathrm{r}^{2}$ & $\mathrm{k}_{\mathrm{H}}$ & $\mathrm{r}^{2}$ & kHC & $\mathrm{r}^{2}$ & $\mathrm{~K}_{\mathrm{kp}}$ & $\mathrm{n}$ \\
\hline Core Tablet & 0.293 & 0.111 & 0.993 & -0.020 & 0.566 & 3.615 & 0.957 & -0.047 & 0.695 & 1.828 & 0.070 \\
\hline F1GG & 0.394 & 0.128 & 0.962 & -0.010 & 0.678 & 3.915 & 0.888 & -0.022 & 0.862 & 1.688 & 0.126 \\
\hline F2GG & 0.505 & 0.143 & 0.948 & -0.006 & 0.779 & 4.155 & 0.889 & -0.014 & 0.935 & 1.540 & 0.182 \\
\hline F3GG & 0.604 & 0.152 & 0.850 & -0.003 & 0.851 & 4.211 & 0.884 & -0.009 & 0.975 & 1.449 & 0.211 \\
\hline
\end{tabular}




\begin{tabular}{|l|l|l|l|l|l|l|l|l|l|l|l|}
\hline F4GG & 0.671 & 0.153 & 0.940 & -0.003 & 0.894 & 4.138 & 0.890 & -0.006 & 0.994 & 1.359 & 0.238 \\
\hline F1TGG & 0.474 & 0.078 & 0.960 & -0.004 & 0.719 & 2.891 & 0.884 & -0.010 & 0.922 & 1.569 & 0.159 \\
\hline F2TGG & 0.595 & 0.090 & 0.969 & -0.003 & 0.824 & 3.158 & 0.896 & -0.007 & 0.957 & 1.398 & 0.220 \\
\hline F3TGG & 0.688 & 0.096 & 0.968 & -0.002 & 0.890 & 3.268 & 0.903 & -0.005 & 0.986 & 1.292 & 0.254 \\
\hline F4TGG & 0.816 & 0.101 & 0.958 & -0.001 & 0.960 & 3.275 & 0.911 & -0.003 & 0.994 & 1.076 & 0.318 \\
\hline
\end{tabular}

The value of release exponent (n) was found to be less than 0.5 indicating diffusion to be the lead mechanism responsible for release of drug through the polymer matrix. Imbibition of media may cause polymeric chains to relax and swell leading to the formation of swollen gelatinous transition state of polymer acting as a barrier for diffusional transport of the drug from within the polymer matrix. Subsequent dissolution of polymeric chain and development of pore/ channel also contributed towards the release of the drug [44, 45].

\section{Conclusion}

Thiolation of gum ghatti was achieved by the ester formation (esterification) between the carboxyl group and hydroxyl group of thioglycolic acid and gum ghatti. Different techniques (FTIR, DSC, XRD, SEM analysis) were employed for characterization analysis of thiolated gum ghattiand rheological studies were executed using rheometer for studying viscosity parameters and their role in mucoadhesion. Compression coated method, a solvent free technique, was employed for coating core tablets of domperidone for developing mucoadhesive sustained release tablets. Thiolated biopolymers exhibit significant bioadhesive and drug release retardant property for developing mucoadhesive drug delivery systems targeting different biological locations viz. gastrointestinal, vaginal, ocular, rectal, pulmonary and buccal for effective drug targeting. Basic properties of the thiolated biopolymers could be altered for being used as potential candidate for developing 3D printed drug delivery systems. Considering the toxicological and regulatory issues related to the modified biopolymers, successful commercial exploitation of the same could be positively explored.

\section{Funding}

The authors received no external funding

\section{Acknowledgments}

The authors kindly acknowledge support and institutional facilities extended by Chitkara College of Pharmacy, Chitkara University, Punjab, India.

\section{Author Contributions}

VP: Experimentation, manuscript writing, analysis, validation

AS: Manuscript writing and editing, methodology, resources

PK: Conceptualization, supervision, revisions, data curation

IS: Conceptualization, supervision, administration, designing experimentation

$\mathrm{KH}$ : Administration, analysis, manuscript editing, funding aquisition

\section{Conflict of Interest}

The authors declare no conflict of interest

\section{Abbreviations \\ $\mathrm{Cu}$




$\begin{array}{ll}\text { DSC } & \text { Differential scanning calorimetry } \\ \text { DTNB } & \text { 5,5'-dithiobis-(2-nitrobenzoic acid) } \\ \text { EDAC } & \text { 1-Ethyl-3-(3-dimethylaminopropyl)carbodiimide } \\ \text { FTIR } & \text { Fourier-transform infrared spectroscopy } \\ \text { GG } & \text { Gum ghatti } \\ \text { HCl } & \text { Hydrochloric acid } \\ \text { KBr } & \text { Potassium bromide } \\ \text { MUC } & \text { Mucin } \\ \text { Ni } & \text { Nickel } \\ \text { OECD } & \text { Organisation for economic co-operation and development } \\ \text { PVP K30 } & \text { Polyvinylpyrrolidone } \\ \text { SEM } & \text { Scanning electron microscope } \\ \text { SGF } & \text { Simulated gastric fluid } \\ \text { TGA } & \text { Thioglycolic acid } \\ \text { TGG } & \text { Thiolated gum ghatti } \\ \text { UV-VIS } & \text { Ultraviolet-visible } \\ \text { XRD } & \text { X-ray powder diffraction }\end{array}$

\section{References}

1. Roy, S.; Pal, K.; Anis, A.; Pramanik, K.; Prabhakar, B. Polymers in mucoadhesive drug-delivery systems: a brief note. Des. Monomers Polym. 2009, 12, 483-495.

2. Singh, I.; Rana, V. Enhancement of mucoadhesive property of polymers for drug delivery applications. Rev. Adhes. Adhes. 2013, 1, 271-290.

3. Badhe, R.V.; Nipate, S.S. Bioadhesives in Drug Delivery, Scrivener Publishing LLC; Hoboken, New Jersey, US, 2020; Chapter 10, pp. 259-305, ISBN 9781119640196.

4. Sharma, M.; Rathore, A.; Sharma, S.; Sadhu, V.; Reddy, K.R.; Kulkarni, R.V. Nanomaterials in Diagnostic Tools and Devices, Elsevier Inc, 2020; Chapter 8, pp. 213-240.

5. Puri, V.; Sharma, A.; Maman, P.; Rathore, N.; Singh, I. Overview of mucoadhesive biopolymers for buccal drug delivery systems. Int. J. App. Pharm. 2019, 11, 18-29.

6. Mendes, A.C.; Sevilla Moreno, J.; Hanif, M.; EL Douglas, T.; Chen, M.; Chronakis, I.S. Morphological, mechanical and mucoadhesive properties of electrospun chitosan/phospholipid hybrid nanofibers. Int. J. Mol. Sci. 2018, 19, 2266.

7. Xu, J.; Tam, M.; Samaei, S.; Lerouge, S.; Barralet, J.; Stevenson, M.M.; Cerruti, M. Mucoadhesive chitosan hydrogels as rectal drug delivery vessels to treat ulcerative colitis. Acta Biomater. 2017, 48, 247-257.

8. de Araujo Pereira, R.R.; Bruschi, M.L. Vaginal mucoadhesive drug delivery systems. Drug Dev. Ind. Pharm. 2012, 38, 643-652. 
9. Deshkar, S.S.; Shirolkar, S.V.; Patil, A.T. Bioadhesives in Drug Delivery, Scrivener Publishing LLC; Hoboken, New Jersey, US, 2020; Chapter 11, pp. 307-369, ISBN 9781119640196.

10. Asati, S.; Jain, S.; Choubey, A. Bioadhesive or mucoadhesive drug delivery system: a potential alternative to conventional therapy. J. drug deliv. Ther. 2019, 9, 858-867.

11. Brannigan, R.P.; Khutoryanskiy, V.V. Progress and current trends in the synthesis of novel polymers with enhanced mucoadhesive properties. Macromol. Biosci. 2019, 19, 1900194.

12. Deshmukh, A.S.; Setty, C.M.; Badiger, A.M.; Muralikrishna, K.S. Gum ghatti: A promising polysaccharide for pharmaceutical applications. Carbohydr. Polym. 2012, 87, 980-986.

13. Zhang, P.; Zhao, Y.; Zhang, X.;Zhu, L.; Fang, Z.; Shi, Q. Thermodynamic properties and state diagram of gum ghatti-based edible films: Effects of glycerol and nisin. Polymers. 2020, 12, 449.

14. Leitner, V.M.; Walker, G.F.; Bernkop-Schnurch, A. Thiolated polymers: evidence for the formation of disulphide bonds with mucus glycoproteins. Eur. J. Pharm. Biopharm. 2003, 56, 207-214.

15. Netsomboon, K.; Jalil, A.; Laffleur, F.; Hupfauf, A.; Gust, R.; Bernkop-Schnürch, A. Thiolated chitosans: Are Cys-Cys ligands key to the next generation?. Carbohydr. Polym. 2020, 242, 116395.

16. Puri, V.; Sharma, A.; Kumar, P.; Singh, I. Thiolation of biopolymers for developing drug delivery systems with enhanced mechanical and mucoadhesive properties: A review. Polymers. 2020, 12, 1803.

17. Bahulkar, S. S.; Munot, N. M.; Surwase, S. S. Synthesis, characterization of thiolated karaya gum and evaluation of effect of $\mathrm{pH}$ on its mucoadhesive and sustained release properties. Carbohydr. Polym. 2015, 130, 183-190.

18. Grewal, P.; Mundlia, J.; Ahuja, M. Thiol modified Moringa gum-A potential bioadhesive polymer. Carbohydr. Polym. 209, 400-408.

19. Bhatia, M.; Ahuja, M.; Mehta, H. Thiol derivatization of Xanthan gum and its evaluation as a mucoadhesive polymer. Carbohydr. Polym. 2019, 131, 119-124.

20. Yadav, S.; Ahuja, M.; Kumar, A.; Kaur, H. Gellan-thioglycolic acid conjugate: Synthesis, characterization and evaluation as mucoadhesive polymer. Carbohydr. Polym. 2014, 99, 601-607.

21. Kaur, H.; Yadav, S.; Ahuja, M.; Dilbaghi, N. Synthesis, characterization and evaluation of thiolated tamarind seed polysaccharide as a mucoadhesive polymer. Carbohydr. Polym. 2012, 90, 1543-1549. 
22. Bhatia, M.; Ahuja, M. Thiol modification of psyllium husk mucilage and evaluation of its mucoadhesive applications. Sci. World J. 2013, 2013, 1-8, Article ID 284182.

23. Borsagli, F.G.M.; Carvalho, I.C.; Mansur, H. S. Amino acid-grafted and $\mathrm{N}$-acylated chitosan thiomers: Construction of 3D bio-scaffolds for potential cartilage repair applications. Int. J. Biol. Macromol. 2018, 114, 270-282.

24. Bernkop-Schnurch, A.; Hornof, M.; Zoidl, T. Thiolated polymers-thiomers: synthesis and in vitro evaluation of chitosan-2-iminothiolane conjugates. Int. J. Pharm. 2003, 260, 229-237.

25. Luo, Q.; Han, Q.; Wang, Y.; Zhang, H.; Fei, Z.; Wang, Y. The thiolated chitosan: Synthesis, gelling and antibacterial capability. Int. J. Biol. Macromol. 2019, 139, 521-530.

26. Thirawong, N.; Kennedy, R. A.; Sriamornsak, P. Viscometric study of pectin-mucin interaction and its mucoadhesive bond strength. Carbohydr. Polym. 2008, 71, 170-179.

27. Amaral, M.; Martins, A. S.; Catarino, J.; Faísca, P.; Kumar, P.; Pinto, J. F.; Pinto, R.; Correia, I.; Ascensão, L.; Afonso, R.A.; Gaspar, M.M. How Can Biomolecules Improve Mucoadhesion of Oral Insulin? A Comprehensive Insight using Ex-Vivo, In Silico, and In Vivo Models. Biomolecules. 2020, 10, 675.

28. Maronpot, R. R.; Davis, J.; Moser, G.; Giri, D. K.; Hayashi, S. M. Evaluation of 90-day oral rat toxicity studies on the food additive, gum ghatti. Food Chem. Toxicol. 2013, 51, 215-224.

29. Publisher Organization for Economic Cooperation and Development (OECD). Guidelines for the Testing of Chemicals, OECD 423. Acute Oral Toxicity-Acute Toxic Class Method. Organization for Economic Cooperation and Development, Paris, 2001.

https://ntp.niehs.nih.gov/iccvam/suppdocs/feddocs/oecd/oecd g1423.pdf [accessed on 05-02-2021]

30. Raza, A.; Shen, N.; Li, J.; Chen, Y.; Wang, J. Y. Formulation of zein based compression coated floating tablets for enhanced gastric retention and tunable drug release. Eur. J. Pharm. Sci. 2019, 132, 163-173.

31. Giri, P.; Singh, I. Development and evaluation of mucoadhesive tablets of cinnarizine using carboxymethylated guar gum by compression coating technique. Biointerface Res. Appl. Chem. 2020, 10, 6365 -6376

32. Malik, D.; Singh, I. Formulation and evaluation of press coated tablets of esomeprazole for colonic delivery. Asian J. Pharm. 2014, 6, 252-258. 
33. Ahuja, M.; Singh, S.; Kumar, A. Evaluation of carboxymethyl gellan gum as a mucoadhesive polymer. Int. J. Biol. Macromol. 2013, 53, 114-121.

34. Costa, P.; Lobo, J.M.S. Modeling and comparison of dissolution profiles. Eur. J. Pharm. Sci. 2001, 13, 123-133.

35. Rani, P.; Sen, G.; Mishra, S.; Jha, U. Microwave assisted synthesis of polyacrylamide grafted gum ghatti and its application as flocculant. Carbohydr. Polym. 2012, 89, 275-281.

36. Stulzer, H.; Rodrigues, P.; Cardoso, T.; Matos, J.; Silva, M. Compatibility studies between captopril and pharmaceutical excipients used in tablets formulations. J. Therm. Anal. Calorim. 2008, 91, 323-328.

37. Rus, L.M.; Tomuta, I.O.A.N.; Iuga, C.; Maier, C.O.D.R.U.T.A.; Kacso, I.; Borodi, G.H.E.O.R.G.H.E.; Bratu, I.; Bojita, M.A.R.I.U.S. Compatibility studies of indapamide/pharmaceutical excipients used in tablet preformulation. Farmacia, 2012, 60, 92-101.

38. Naveen, N. R.; Gopinath, C.; Kurakula, M. Okra-Thioglycolic Acid Conjugate-Synthesis, Characterization, and Evaluation as a Mucoadhesive Polymer. Processes. 2020, 8, 316.

39. Vieira, J.M.; Mantovani, R.A.; Raposo, M.F.J.; Coimbra, M.A.; Vicente, A.A.; Cunha, R.L. Effect of extraction temperature on rheological behavior and antioxidant capacity of flaxseed gum. Carbohydr. Polym. 2019, 213, 217-227.

40. Nowak, J.; Laffleur, F.; Bernkop-Schnurch, A. Preactivated hyaluronic acid: a potential mucoadhesive polymer for vaginal delivery. Int. J. Pharm. 2015, 478, 383-389.

41. Jalil, A.; Asim, M.H.; Le, N.M.N.; Laffleur, F.; Matuszczak, B.; Tribus, M.; Bernkop-Schnurch, A. S-protected gellan gum: Decisive approach towards mucoadhesive antimicrobial vaginal films. Int. J. Biol. Macromol. 2019, 130, 148-157.

42. Bernkop-Schnurch, A.; Kast, C.E.; Richter, M.F. Improvement in the mucoadhesive properties of alginate by the covalent attachment of cysteine. J. Control. Release. 2001, 71, 277-285.

43. Laffleur, F.; Michalek, M. Modified xanthan gum for buccal delivery-a promising approach in treating sialorrhea. Int. J. Biol. Macromol. 2017, 102, 1250-1256.

44. Barmpalexis, P.; Kachrimanis, K.; Malamataris, S. Statistical moments in modelling of swelling, erosion and drug release of hydrophilic matrix-tablets. Int. J. Pharm. 2018, 540, 1-10. 
45. Hattori, Y.; Takaku, T.; Otsuka, M. Mechanochemical effect on swelling and drug release of natural polymer matrix tablets by $\mathrm{X}$-ray computed tomography. Int. J. Pharm. 2018, 539, 31-38. 